\title{
THE OCCURRENCE OF BLACK NECROTIC DISEASE IN CRAB SPECIES FROM THE WEST OF SCOTLAND
}

\author{
C. A. Comely E'A. D. Ansell \\ Scottish Marine Biological Association, \\ Dunstaffnage Marine Research Laboratory, P. O. Box 3, Oban, Argyll, Scotland, PA34 4AD
}

\begin{abstract}
ABSTRAC'T
The incidence of Black Necrotic Disease affecting a) the carapace and other areas of the external skeleton, and b) the gills, was recorded for crab species from sites on the west coast of Scotland. The highest incidence of carapace infection was found in Cancer pagurus, with Carcinus maenas, Liocarcinus puber, $L$. corrugatus and $L$. depurator showing a lower incidence; other species of crabs, especially from sandy habitats, and species of Natantia showed no infection. The highest incidence of gill disease was in $L$. depurator and L. corrugatus, while L. puber and Hyas arenarius showed a lower occurrence; other species of crabs, and species of Natantia showed very low or zero incidence. The percentage incidence and severity of attack apparently was not dependent on depth of capture, nor was there any significant seasonal pattern of variation, but some species showed significant differences in percentage incidence between the sexes, and Carcinus maenas parasitised by the rhizocephalan Sacculina carcini showed a higher incidence than those which were not infested with this parasite.
\end{abstract}

\section{INTRODUCTION}

In recent years the condition variously referred to as Black Necrosis (Perkins 1967), Shell Disease (Cook \& Lofton 1973, Roald et al. 1981) and Black Spot (Ayres \& Edwards 1982) has been well documented, and most if not all commercially exploited crustaceans have been found to exhibit symptoms of the disease, including penaeid prawns (Cook \& Lofton 1973), shrimps (Schlotfeldt 1972, Abbott 1977), lobsters (Young \& Pearce 1975, Roald et al. 1981), and crabs (Pearson 1908, Perkins 1967, Ayres \& Edwards 1982).

In British waters Pearson (1908) first described the condition in the edible crab (Cancer pagurus L) from the Isle of Man fishery. Perkins (1967) recorded the condition in Carcinus maenas (L) from the Solway Firth, where up to $7.1 \%$ of crabs with a carapace width $>30 \mathrm{~mm}$ were infected, and from the Gareloch (Firth of Clyde), where the infection rate exceeded $50 \%$. These observations presumably referred to animals in which the lesions were readily visible. Abbott (1977) studied the incidence of the disease affecting the shrimp Crangon crangon $(\mathrm{L})$ in the 
Solway Firth, and Ayres \& Edwards (1982) gave a generalised account of the condition in stocks of Cancer pagurus from the eastern and southern coasts of England and south west and west coasts of Ireland. From eastern England $<1 \%$ of the catch was rejected because of Black Spot, $<2 \%$ from the south coast, but $5-7 \%$ were rejected from the Irish fishery.

Although a similar disease seriously affects American lobster stocks, there appears to be no records of Black Necrotic Disease affecting the European lobster Homarus gammarus (L) apart from the report by Fisher (1977) and the interesting paper by Roald et al. (1981) on Norwegian lobsters.

These published reports all refer to the disease as it affects the carapace of the crustacea involved and/or in some cases the limbs. A related condition, in which damage is manifested as erosion of the gills, has been reported in the American lobster (Sawyer \& Taylor 1949), and also in shrimp (Lightner 1977), but has not been reported previously for crustacea from Scottish waters.

The consensus of opinion at the present time is that the causative organism of both carapace and gill conditions is one or more of the chitinoclastic bacteria which have been isolated from the lesions, and that associated fungi are secondary invaders (Rosen 1967, Cook \& Lofton 1973, Fisher et al. 1976, 1978). Critical reading of the descriptions of the condition given by various authors show some discrepancy. Rosen (1970) referred to the lesions as being brown marks with depressed reddish brown centres, to which the terms of Burned Spot and Rust were aptly given. He claimed that penetration of the endocuticle by the necrosis did not occur, even in the most severe cases which he examined (and figured), and also says that no cases of remission were known. Other descriptions involving American material show general agreement with Rosen's description, the emphasis being on the brown, rusty appearance, as for example Cook \& Lofton's record (1973) of a soft brown lesion on shrimps. In European descriptions the emphasis is on the black nature of the lesion, often associated with perforation of the shell (Pearson 1908, Schlotfeldt 1972, Abbott 1977, Ayres \& Edwards 1982).

Because of the overwhelmingly commercial bias in the interest in this disease, references tend to concentrate on the external signs, the internal condition only being commented on in the extreme condition when perforation of the exoskeleton has occurred. Consequently the origin of the disease tends to be referred to as external, related primarily to injury, especially in a farm environment (Sindermann 1977). The cause of the infection of the gills resulting in the destruction of the gill structure in various shrimp species and in Homarus americanus (MilneEdwards) which have either been farmed, or kept for substantial periods of time in crowded conditions has been variously assigned to black necrotic disease, fungal infections or heavy metals (Uzmann \& Haynes 1968, Rinaldo \& Yevich 1974, Fisher 1977, Lightner 1977).

During an investigation into the distribution of various crab species in part of the Firth of Lorne, on the west coast of Scotland, Black Necrotic Disease was 
found affecting the external skeleton of not only Cancer pagurus but also the highly valued velvet crab Liocarcinus puber (L), the shore crab, Carcinus maenas, as well as other less commercial species. In addition, individuals of the small swimming crab, Liocarcinus depurator $(\mathrm{L})$ were found in which the gill lamellae had been completely eroded, only the blackened gill rachi remaining. This gill condition was also wide-spread amongst some other crab species - albeit with less extreme symptoms.

Because of the increasing commercial demand for crab species from the Scottish west coast, the occurrence of this disease has been looked at in more detail, and this paper reports the results of a survey of rates of infection in both commercially exploited and other crustacean species from the Firth of Lorne area.

We are grateful to our colleague Dr A. M. Bullock for the histological examination of gills and for the photographs reproduced in Fig. 3, the skipper and crew of the M. V. "Seol Mara" for their assistance in this investigation and to Mrs. L. Robb for technical help. The work was supported by the Natural Environment Research Council.

\section{LOCATION AND METHODS}

Crabs were caught in baited crab creels with an aperture diameter of $80 \mathrm{~mm}$, which were laid routinely at depths of 5,10,15 and $25 \mathrm{~m}$. The creels were set at regular monthly intervals, from December 1985 until June 1987 at Eriska, immediately to the south of the entrance to Loch Creran, and also from May 1986 at a site immediately to the east of the Lismore Lighthouse in the Lynn of Lorne (Fig. 1). The length and width of the carapace of all crabs caught were measured to the nearest $0.10 \mathrm{~mm}$, and the animals sexed and examined for associates or parasites - in particular the rhizocephalan Sacculina carcini Thompson, and the eunicid polychaete Iphitime cuenoti Fauvel (Comely \& Ansell, in prep.). The crab carapaces were retained after cleaning, and subsequently examined for signs of shell necrosis; it was not possible to routinely assess the incidence of the disease affecting the limbs or ventral skeleton in the time available. Search of the internal surface of the carapace was adopted for routine assessment of infection since it was found that the disease is apparent internally before there is any noticeable indication on the external surface. In order to assess the relative severity of the infection, the area of carapace affected in individual crabs was plotted within a standardised crab outline using squared paper, and the percentage of the total carapace area affected calculated (Fig. 2A). The results do not include infections of the sub-hepatic or pterygostomial regions unless specifically stated otherwise; the numbers of crabs infected in these regions alone were very few. In order to obtain a fuller assessment of the degree of infection involving limbs and ventral skeleton, a single collection of Carcinus was obtained in June 1988, and all parts of the exoskeleton were examined for the disease. 


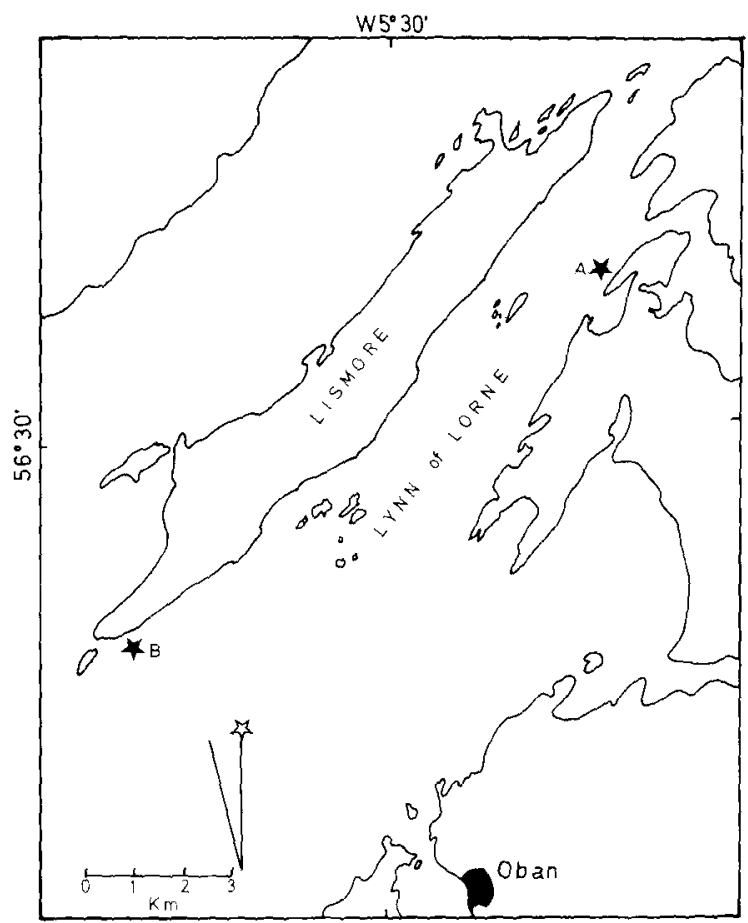

Fig. 1. Area map to show sites at which crabs were collected. A: Eriska, B: Lismore.

The degree of severity of the affect of the disease on the gills was estimated on a scale of $1-4$, where $1=\leq 5 \%$ of total gill area, $2=6-25 \%, 3=25-75 \%, 4=$ $>75 \%$.

\section{RESULTS}

\section{Symptoms}

\section{Carapace lesions.}

The characteristic lesion found on the internal surface of the carapace in all crab species was a black spot, initially more or less circular, but often becoming more irregular in outline when it exceeded about $1 \mathrm{~mm}$ in diameter. At this early stage the spot was seldom manifest on the external surface. The infection may apparently be contained at this stage by a capping of calcareous material which isolates the lesion, and the small ( $<2 \mathrm{~mm}$ ) calcareous discs, usually with a slightly concave centre, which result from this process were common in otherwise seemingly healthy crabs, suggesting that containment of the disease is frequently successful. In crabs which had recently moulted there was often a halo of orange or purple pigmentation about the loci of infection, including those which had been contained apparently successfully. In the rather small specimens of Cancer pagurus which were caught these coloured haloes were very common, and similar coloura- 


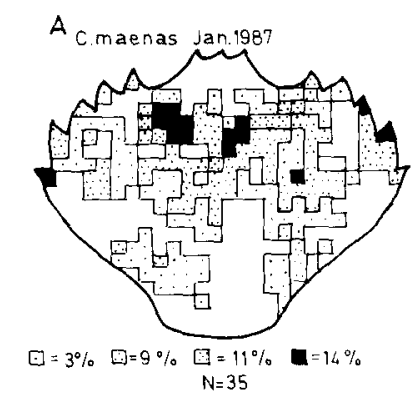

$R$

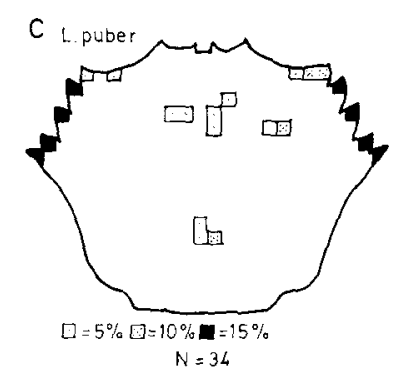

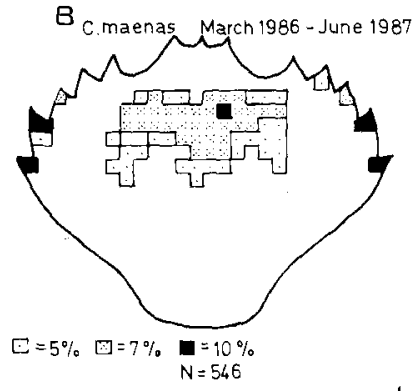

L

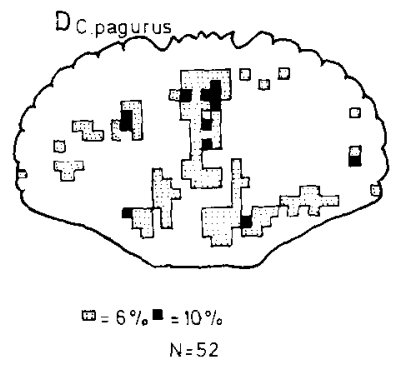

Fig. 2. The standardised internal carapace outlines used to map the areas affected by Black Necrotic Disease in the three crab species mainly affected. Note that these plots relate to the INTERNAL carapace. $\mathrm{R}=\mathrm{Right}$ $\mathrm{L}=$ Left side of carapace. A. Carcinus maenas. The result obtained in January 1987, with 35 infected crabs. B, C $\&$ D. The combined results for C. maenas, Liocarcinus puber and Cancer pagurus for infected crabs caught during the entire period of investigation.

tion was repeatedly observed affecting irregular areas in which there was no black locus of infection.

With increasing size, the lesion may perforate the shell, becoming evident externally first as a general discolouration, and finally as a black area formed by a parchment-like membrane. The external lesions seen were almost invariably smaller than the area of the lesion internally.

In some instances a lesion apparently may extend with no indication of secondary loci of infection developing. More usually, several spots develop and, in extreme cases, these appear to have expanded and coalesced until only islands of seemingly healthy skeleton are left, together with white calcareous plaques indicating where unsuccessful attempts at containment have taken place.

Infection associated with wounds could usually be recognised by the irregular and often angular boundary and roughened edges of the affected area. The majority of loci, however, appeared to be generated internally. In the chelae it was more difficult to assess the aetiology of the disease. Penetrative and abrasive injuries were relatively common, but as on the carapace, small loci of infection did occur. 
In general it appears that the disease is as evident or even more evident on the external surface of the chelae than on the internal surface, but it is very difficult to make accurate observations, as any such attempt involves considerable destruction of the limb.

The part of the external skeleton in which the disease was most manifest varied between the different crab species (Fig. 2). When the results of the infected Carcinus maenas examined (546) are amalgamated, the areas of main susceptibility are well defined (Fig. 2B). The main concentration of the infection was consistently in the anterior half of the carapace, mainly involving the meso- and protogastric regions, and extending into areas of the epibranchial and metagastric regions. The anterio-lateral spines, especially the three most posterior, also showed a high incidence of the disease.

There were too few infected Liocarcinus puber and Cancer pagurus ( 34 and 52 respectively) in the collections to give a complete indication of the most susceptible areas of the carapace (Fig. 2C, D). Only areas of the carapace in C. pagurus which were pigmented black were used for mapping. As in $C$. maenas an area near the mid line seemed to be particularly susceptible, but in general the areas subject to infection were more wide-spread, and did not show the concentration in the anterior part of the carapace which was characteristic of $C$. maenas. The peripheral indented areas in $C$. pagurus were remarkably free of infection. In contrast, in $L$. puber the carapace spines appeared to be notably vulnerable to infection. The anterio-medial area in $L$. puber also appeared to be susceptible, but the data were insufficient to fully quantify this. In both Liocarcinus corrugatus (Pennant) and $L$. depurator the numbers of infected crabs were too small to indicate any concentration of area most affected.

The diseased area of individual carapaces measured in C. maenas varied from a small isolated spot $<1 \mathrm{~mm}$ in diameter, to as much as $35 \%$ of the carapace, either as a major lesion or the cumulative area of several lesions. Areas of local healing were common, but this generally only appeared to be successful in small lesions (1-2 mm); in larger lesions the infection was rarely contained, extending out from the periphery of the repaired area so that large lesions often had islands of repaired carapace more or less surrounded by active areas of necrosis. Even in newly moulted crabs the repaired areas could be readily identified.

In order to assess the true incidence of black necrotic disease in the $C$. maenas population, 178 crabs caught in June 1988 at a depth of $5 \mathrm{~m}$ were examined on all parts of the exoskeleton for any sign of infection. A large proportion (38.8\%) proved to be recently moulted males; of these, 11 (15.9\%) showed evidence of the disease, and in 8 of these $(72.7 \%)$ the disease was apparently still active. Lesions were found on 60 of the crabs (33.7\%), and the distribution of the disease is shown in Table 1.

During routine investigations only the sites of disease affecting the carapace not including the sub-hepatic and pterygostomial plates, were recorded. In the 
Table 1 . The percentage occurrence of Black Necrotic Disease on various areas of the exoskeleton of Carcinus maenas caught in June 1988.

\begin{tabular}{lcc}
\hline & $\mathrm{N}$ & $\%$ \\
Total number of crabs caught & 178 & - \\
Total number of crabs infected & 60 & 33.7 \\
\hline Total number of crabs infected & 60 & - \\
Total number of carapaces infected & 39 & 65.0 \\
Total number with infected chelae & 26 & 43.3 \\
Carapace only infected & 29 & 48.3 \\
Chelae only infected & 16 & 26.7 \\
Pereiopod 2-5 only infected & 1 & 1.7 \\
Ventral area of exoskeleton only & 5 & 8.3 \\
Sub-hepatic and pterygostomial regions only & 2 & 3.3 \\
\hline
\end{tabular}

June collection this method of assessment gave a value of $21.9 \%$ of crabs infected. As a proportion of all the crabs known to be affected they accounted for $65.0 \%$, which means that $35 \%$ were affected in areas of the exoskeleton other than the carapace. In only $26.7 \%$ of infected crabs was the disease restricted to the chelae, compared to $48.3 \%$ in which the infection was apparently confined to the carapace. Other areas of the skeleton, particularly the walking legs (pereiopods $2-5$ inc.) had a very low percentage of infection. However, whilst the recognition of the disease on the internal surface of the carapace is considerably easier than on the outer surface, this method of determination is not possible on the other areas of the exoskeleton, and the comparative incidence of the disease is almost certainly routinely underestimated as a consequence.

\section{Gill symptoms.}

The characteristic appearance of the disease as it affected the gills was of brown and black bands which mainly encroached on the lamellae from the edges, although central areas of infection were also common. In light infections a single affected gill lamella was all that was noticeable, but in more severe cases entire areas of adjacent lamellae were infected, forming distinctive blackened areas on the gill. At this stage more than one gill was invariably affected. The most extreme cases seen were where the lamellae were completely missing, only the blackened gill rachi being left. More usually the lamellae, although blackened and brittle, were still present, but showed signs of erosion at the edges.

Histological examination of affected gills showed the occlusion of the gill lumen by a melanotic mass of unknown origin (Fig. 3). Fungal stains failed to confirm that hyphae were present. No microbiological techniques were applied.

In Liocarcinus depurator, the encysted larvae of a nemertine, presumably Carcinonemertes carcinophila (Kolliker), were found to be present on the gills, often in considerable numbers, but there was no evidence of any direct relationship between the occurrence of the parasite and the disease, although the edges of the cysts often appeared to be a focus for the infection. 

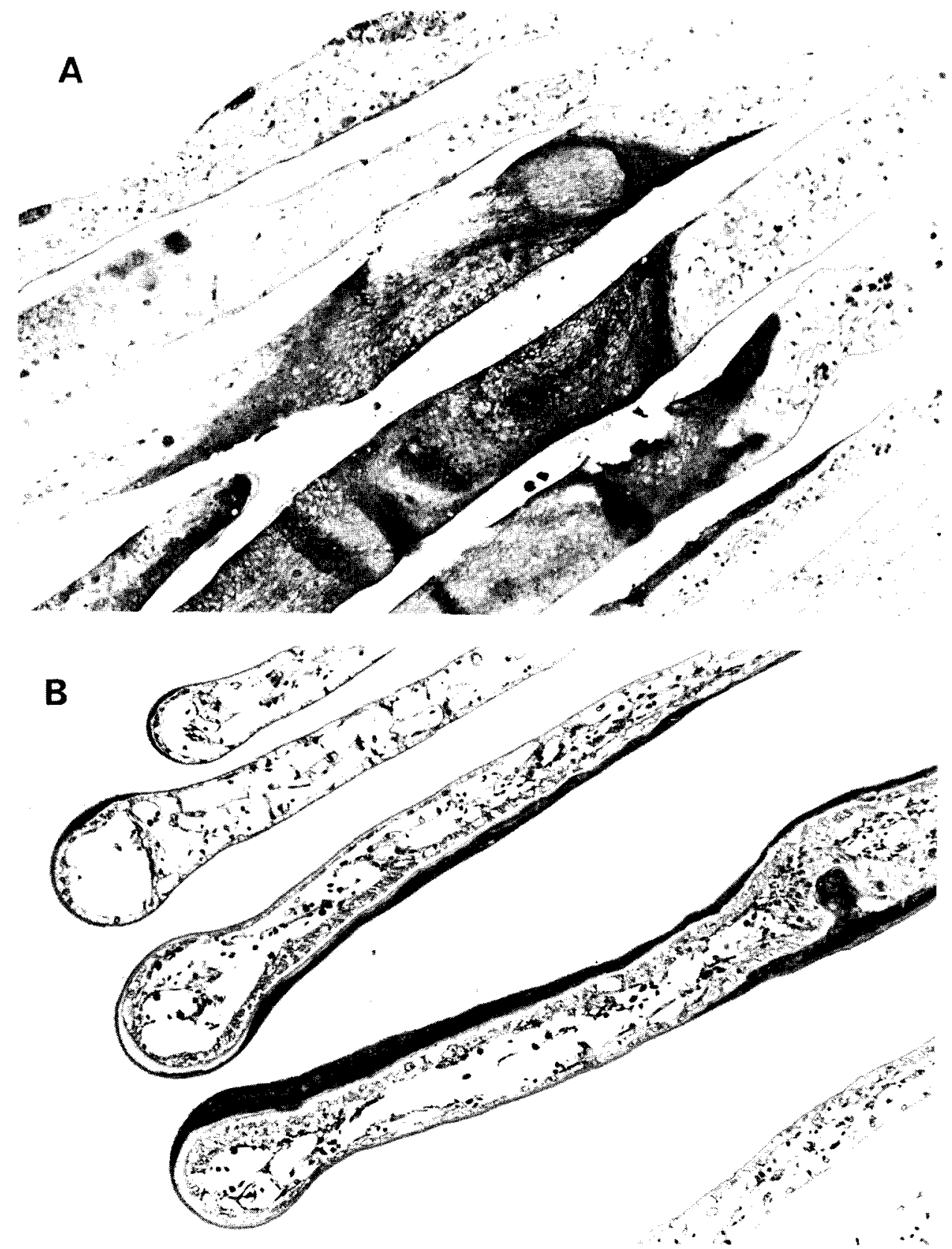

Fig. 3. Histological sections of infected gills, stained with haematoxylin and eosin, from: A. Liocarcinus depurator; $\mathrm{B}$, L. corrugatus. 


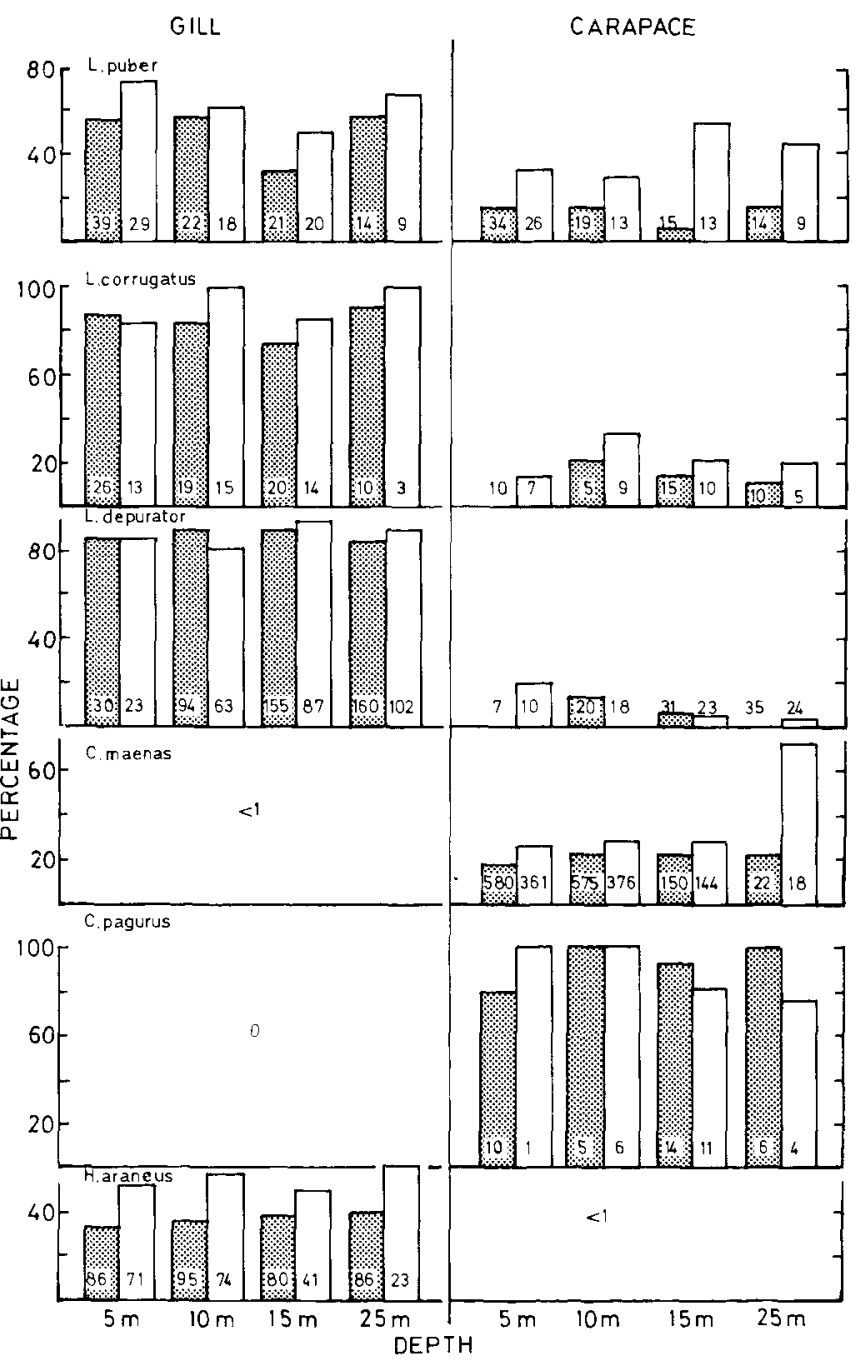

Fig. 4. The percentage gill and carapace infection of six species of crabs related to depth and sex. The total number of crabs involved are shown in each column. Shaded: Male; white: Female.

\section{Incidence of infection in different species}

The overall incidence of infection of the carapace and of the gills in each of the crustacean species examined throughout the course of this investigation is summarised in Fig. 4.

The percentage of crabs showing black necrosis on the carapace ranged from nearly $100 \%$ for Cancer pagurus to only $6 \%$ in Liocarcinus depurator. Only one infected individual of Hyas araneus (L) was found, representing $0.25 \%$ of the catch. 


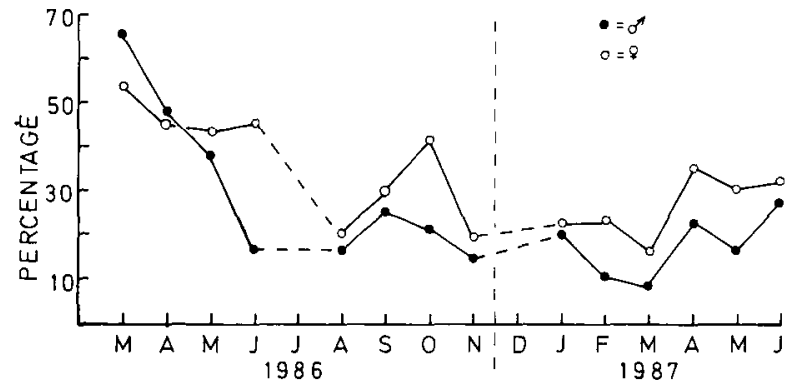

Fig. 5. The seasonal variation in percentage occurrence of black necrosis affecting the carapace of C. maenas.

Several hundred individuals each of Nephrops norvegicus (L), and Munida rugosa (Fabricius) were caught with, and examined at the same time as, the crabs without any sign of the disease being found.

Of several hundred Liocarcinus holsatus (Fabricius) examined from the east coast of Scotland, only one, with three very small spots on the inner carapace, showed any evidence of the disease, while collections of Crangon crangon from local and east coast beaches also showed no sign of the disease.

Infection of the gills was found in Liocarcinus depurator, L. corrugatus, L. puber and in $H$. araneus. $C$. maenas was almost completely free of the condition, only two or three affected specimens being found in the several hundred crabs examined, and there were no records of the gills of $C$. pagurus being affected.

\section{Factors affecting the incidence of infection}

Depth of capture.

Analysis of the data on the incidence of both carapace black spot and gill damage for crabs caught at different depths shows that there was no clearly defined relationship between the depth of capture and the occurrence of the disease in any individual species (Fig. 4) although the number of crabs of each species caught was depth dependent. Twice as many L. puber were obtained at $5 \mathrm{~m}$ as were obtained in any one of the other depths fished, whilst $L$. depurator and possibly $L$. corrugatus favoured depths of $15 \mathrm{~m}$ or more. C. maenas was caught in greatest numbers in the shallower depths, the numbers falling considerably at $15 \mathrm{~m}$, and few were caught at $25 \mathrm{~m}$. The numbers of $C$. pagurus caught were too small to be significant, but the fact that over twice as many were caught in the $15 \mathrm{~m}$ zone, the lower boundary of the Laminaria with the deeper water, than at any other depth fished may be biologically significant (Comely \& Ansell 1988).

\section{Seasonality.}

In none of the crab species was there any clearly defined seasonal relationship in the percentage incidence of carapace black spot or gill damage (Figs 5 and 6) although in all cases there was considerable monthly variation in percentage incidence. 
Table 2. Summary of the overall percentage occurrence of black necrosis affecting the carapace and gills of different species of crustacea from two sites in the Firth of Lorne, west coast of Scotland.

\begin{tabular}{lrrrrr} 
& \multicolumn{2}{c}{$\%$ with } & \multicolumn{2}{c}{$\%$ with } \\
Carapace Symptoms & \multicolumn{2}{c}{ Gill Symptoms } \\
Species & Male & Female & Male & Female \\
\hline Liocarcinus puber & 14.6 & 39.4 & 52.1 & 63.2 \\
L. depurator & 9.1 & 9.3 & 89.5 & 89.8 \\
L. corrugatus & 11.3 & 22.6 & 84.0 & 91.1 \\
L. holsatus & 0 & 0 & 0 & 0 \\
Carcinus maenas & 19.9 & 28.1 & & $<1 \%$ & 0 \\
Cancer pagurus & 89.8 & 72.3 & 0 & 55.0 \\
Hyas arenarius & & 0.25 & & 37.5 & 0 \\
Nephrops norvegicus & 0 & 0 & 0 & 0 \\
Munida rugosa & 0 & 0 & 0 & 0 \\
Crangon crangon & 0 & 0 & 0 & \\
\hline
\end{tabular}

Differences between the sexes.

In Liocarcinus puber, L. corrugatus and C. maenas a higher proportion of female than of male crabs were found to be affected by carapace black necrosis. In $L$. depurator the proportion affected was equal in the two sexes, while in $C$. pagurus, although a higher proportion of males were found to be affected, the difference between the sexes was not significant (Table 2). The difference between the sexes in L. puber, L. corrugatus, C. maenas and C. pagurus remained consistent at different depths (Fig. 4). In C. maenas the difference was consistent from month to month (Fig. 5).

The incidence of gill damage also differed between the sexes. There was a higher overall number of female $L$. depurator with gill disease than males (Table 2), and this difference was consistently repeated in those months in which sufficient numbers of both sexes were caught to provide a valid comparison (Fig. 6).

Sacculin a infestation.

The biology of Carcinus maenas is considerably influenced by the occurrence of the parasite Sacculina carcini which interferes not only with the sexual cycle, but more importantly in the context of this investigation, with the moulting cycle (Caullery 1952, Crothers 1968). During this investigation, considerable variations were found between months in the percentage incidence of Sacculina infested crabs, but

Fig. 6. The seasonal variation in percentage occurrence of gill necrosis in L. depurator.

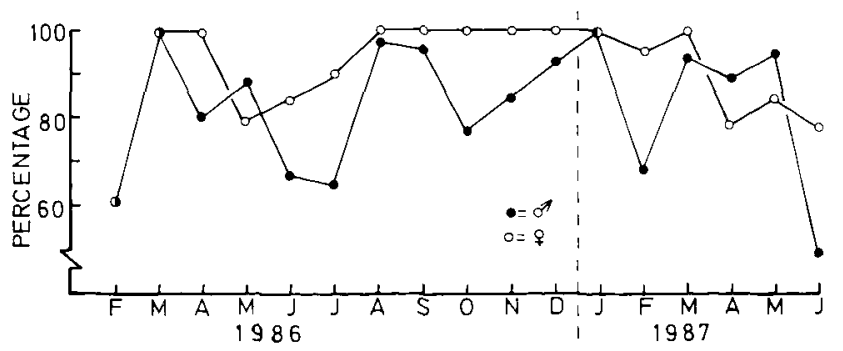


Table 3. The percentage infestation of Carcinus maenas from different depths with Sacculina (\% Sac), and the percentage of infected crabs showing Black Necrotic Disease of the carapace (\% BND).

\begin{tabular}{ccccccc}
\hline & \multicolumn{2}{c}{ Male } & \multicolumn{2}{c}{ Female } & \multicolumn{2}{c}{ Total } \\
Depth $(\mathrm{m})$ & \% Sac & \% BND & \% Sac & \% BND & \% Sac & \% BND \\
\hline 5 & 29.0 & 43.0 & 30.2 & 36.6 & 29.9 & 39.9 \\
10 & 40.4 & 54.5 & 44.4 & 51.0 & 41.9 & 52.9 \\
15 & 55.3 & 79.9 & 45.8 & 46.3 & 50.7 & 61.3 \\
25 & 83.3 & 40.0 & 77.8 & 61.5 & 72.5 & 55.6 \\
Mean & 37.8 & 53.1 & 39.5 & 45.4 & 38.5 & 49.3 \\
\hline
\end{tabular}

there was no readily determinable seasonal variation (Table 3). A disproportionate number of sacculinised crabs are seen to suffer from necrosis, and there is a higher incidence of parasitisation and associated infection associated with the fewer crabs caught in the deeper waters.

\section{Severity of infection}

The severity of damage to the carapace by black necrotic disease varied greatly from individual to individual and between species. In the most severely affected C. maenas found, over $35 \%$ of the carapace was affected, whilst in $L$. corrugatus approximately $14 \%$ of the carapace was damaged. In $L$. puber the most severe damage seen in the main study affected only $5 \%$ of the carapace, but in September 1988 a number of severely affected velvet crabs commercially fished in the Sound of Mull were examined: three females which died whilst being clasped by males during the initial stages of moult all had lesions occupying up to $25 \%$ of the carapace area, while the surviving crabs, which had shown no signs of moulting, were equally badly affected. In the most severely affected $L$. depurator $4 \%$, and in the only affected specimen of Hyas araneus $5 \%$ of the carapace was affected, whilst in C. pagurus, which were all relatively small, the largest area affected accounted for $17 \%$ of the carapace. For the total C. maenas population the mean area of infected carapace for a standardised crab for each month varied from $0.50 \%(\mathrm{n}=$ 29) to $1.27 \%(\mathrm{n}=17)$ (Fig. 7), but of the 15 months for which records are available, 10 had values between $0.52 \%(\mathrm{n}=92)$ and $0.75 \%(\mathrm{n}=30)$. There was no consistent variation in the monthly mean area of infection which might indicate seasonality. The mean value for all months, including June 1988, was $0.71 \%$.

The severity of gill infection in each crab was estimated on a scale of $1(5 \%)-$ $4(>75 \%)$ of gill area. A single $L$. depurator with a Grade 4 infection was recorded in October, and two in December 1986; both were males and both were caught at a depth of $15 \mathrm{~m}$. Although the numbers of crabs infected, particularly females, were relatively small there is some indication of an increase in the severity of the disease in female crabs in September, and in males in November. The monthly 
Fig. 7. The monthly mean percentage area of carapace affected by black necrosis in $C$. maenas.

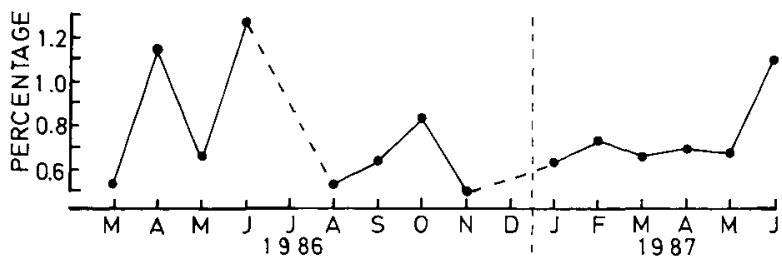

mean severity for each of the four crab species is shown in Fig. 8. L. depurator showed the lowest degree of severity in April, May and June, and a peak in October and November (approximately), but in general the values did not indicate any clear seasonal fluctuations.

\section{DISCUSSION}

Pearson (1908) commented on the occurrence of 'Granny Crabs' suffering from shell necrosis in the waters around the Isle of Man, and stated that not only were they unsightly but that the flesh had a bitter taste so that they were discarded by the fishery. Subsequent investigations concentrated on the microbiological aspects of the disease, particularly as it affected the increasingly important farming of commercial species in America. Surprisingly little information is available on the occurrence of the disease in natural populations, and nothing is known regarding its importance either to the natural population of susceptible animals, or to the fishery.

The present observations show that on the Scottish west coast, a disease, or diseases producing symptoms of shell and gill damage is widespread among various crab species. Shrimps, prawns, lobsters and squat lobsters in the area are completely free of the disease, or show such a low incidence as to be negligible. Liocarcinus spp. are particularly subject to gill disease, whilst Carcinus maenas, a closely related species, is very rarely affected by gill disease, but is very seriously affected by shell necrosis. Cancer pagurus suffers from shell necrosis, but no case of gill dis-

Fig. 8. The monthly mean severity of gill necrosis in the four crab species most affected. $1=\leq 5 \% ; 2=\leq$ $25 \%$ of gill area affected.

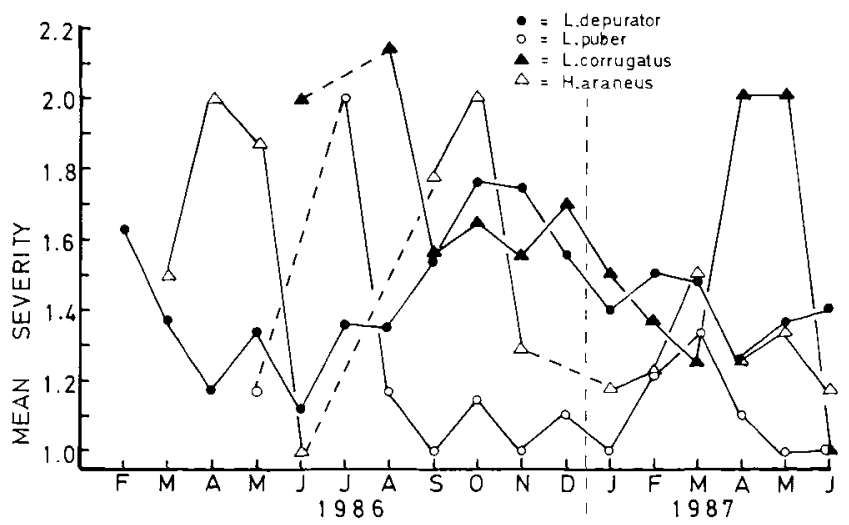


ease is known, and Hyas araneus suffers from gill disease, but is rarely affected by shell necrosis. It would be very interesting to know what the common denominator is for susceptible and resistant animals, but the results clearly raise doubts that a single causative factor is involved.

The lack of black necrotic disease in the Natantia from the Firth of Lorne and from St. Andrews Bay examined here is in marked contrast to the observations of Abbott (1977) for Crangon crangon in the Solway Firth, and for other species elsewhere (Schlotfeldt 1972, Cook \& Lofton 1973, Gopalan \& Young 1975, Lightner 1977). Abbott (1977) makes a very good case for the incidence of the disease in Crangon from the Solway Firth being related to damage done to the pre-fishery sized animals by the fishing gear and subsequent handling. Other workers have implicated pollution, for example by the dumping of organic wastes, in the incidence of the disease (Young \& Pearce 1975, Roald et al. 1981). There is no commercial exploitation of the shrimp in the areas studied here, nor is there any considerable dumping of organic matter.

Although recorded in cultured prawns and tank-held $H$. americanus (Sindermann 1977) gill disease does not appear to have been recorded previously in crabs, probably because on casual investigation it appears to be a superficial 'sooty' condition as found in crabs from the New York Bight (Lightner 1977). In the present investigation, the extraordinary sight of a crab branchial cavity occupied solely by blackened gill rachi drew attention to this as a true disease syndrome. The disease has now been shown to be relatively wide-spread in Liocarcinus species. The destruction of the gills in this manner may well result in reduced respiratory function, and be a contributory factor to the poor survival of $L$. puber during transportation (Whyman et al. 1985). The occurrence of heavy infestations of nemertine larval cysts does not appear to be necessarily a contributory factor, moults of $L$. depurator examined showing that the cysts and the associated blackened areas are superficial; the fate of crabs with diseased gills can only be surmised as no moults from such crabs have been found. The eunicid polychaete Iphitime cuenoti is a common inhabitant of the branchial cavity of $L$. puber and $L$. depurator, is rarely found in Carcinus and Hyas, and very rarely in Cancer (Comely \& Ansell in prep.). Whether is causes damage to the gills during the course of its feeding is a matter of conjecture since nothing is known of its feeding habits, but if it does suck the blood of it's host as has been suggested, this could be a factor predisposing the host crabs to the disease.

The method of infection by the causative organisms remains a matter of debate. Hess (1937) isolated a number of specific fungi from three species of infected fresh water decapods, and succeeded in inducing infection in healthy animals following injections of the fungal spores. Subsequent American investigators concluded that in marine species fungi were secondary invaders, and that the main causative organisms were bacterial. However, the experimental proof has been ambiguous. Sindermann \& Rosenfield (1967) cite an unpublished report by 
Bright et al. (1960) on the successful infection of healthy Alaskan King Crabs (Paralithodes spp.) following the introduction of bacterial isolates from infected crabs to areas of mechanical injury on the carapace. Cook \& Lofton (1973) also achieved positive results after inducing mechanical damage to Callinectes sapidus Rathbun; not only the crabs exposed to the causative organisms, but also the control animals became infected! Apparently inoculation of crabs has not been carried out in this more recent work. The American workers seem to be agreed that the disease in crabs and, more importantly as far as they are concerned, the lobster, is lost with the moult (Sindermann 1977), the animal having to be re-infected after moulting, because the disease does not pass the endocuticular barrier. The disease appears to be temperature dependant, higher incidences of the disease being apparent during the late summer, leading to considerable mortalities, at least in commercial conditions, (Sindermann \& Rosenfield 1967, Rosen 1970, Sindermann 1977). Apart from an unpublished student report on the incidence of black necrosis in Cancer pagurus from the British east coast, and a bacteriological investigation of the lesions (McIntosh 1963), there is apparently no European literature relating to the aetiology of the marine disease. The American descriptions emphasise the reddish-brown, rusty appearance, and the pitting of the exoskeleton which apparently affects the entire skeleton - dorsal, ventral and appendages non-preferentially. The British descriptions emphasise the black nature of the lesions, usually associated with the chelae but also, and as prevalently, affecting the dorsal carapace. The lesions frequently perforate the exoskeleton, and the condition is carried over from the pre-moult to the post-moult animal (Schlotfeldt 1972). The results presented here indicate that the disease causing shell damage to crabs on the west coast of Scotland is similar to that described from elsewhere in the British Isles. The evidence indicates that the disease is carried over during the moult, and that the disease can be contained during the early stages, although whether this represents a permanent cure is not known.

The American evidence points to the perforation of the inert epicuticle as the main portal of entry, Rosen (1970) suggesting that the bacteria invade the exposed chitin layer, creating a microhabitat suitable for secondary pathogens, but there is no indication that the disease is to be regarded as anything other than an opportunistic invasion of the exoskeleton. Whilst the histological evidence supports this supposition, it is difficult to relate it to the descriptive and pictorial evidence of Rosen (1970), showing the numerous small isolated circular lesions, and this is equally true for the observations in the British Isles. In those areas of the body which are susceptible to damage, for example the legs, in particular the chelae which are the crabs' first means of offence and defence as well as being used extensively for preparing food items prior to ingestion, damage and consequent infection can be anticipated, but infection of the carapace is more problematic, as it is less likely to be damaged, especially in a manner to produce multiple loci of infection - spots, which give rise to the common name Black Spot Disease (Ayres 
\& Edwards 1982) - as figured by Rosen. Such numerous scattered loci would seem to indicate a systematic disease, and not solely a multiple opportunistic infection. The description of bitter and purgative flesh by Pearson (1908) also suggests a more deep seated origin of the external manifestation of the disease. That the portal of entry is probably a wound which can occur on any part of the body is not in question, but the subsequent course of the disease is, on the evidence, very much in doubt. Sindermann \& Rosenfield (1967) state that of more than thirty chitinivorous bacteria known at that time, a half had been isolated from crustacea; the pathogenicity of these presumably has still to be tested.

The successful inoculation experiments of Mann \& Pieplow (1938) with fungal infection of fresh water decapods indicate a systematic distribution of the disease following an initial mechanical infection. The fact that in the American experience the disease does not pass the endocuticular barrier during moults unlike the European observations, would suggest that either the disease organism(s) in European crustaceans are different, having a systematic capability, or that the crustaceans do not have the ability to prevent organisms passing the postulated barrier (Rosen 1970, Lightner 1977, Fisher 1977). Either way, there seems to be too much reliance on the American results, which are probably not directly applicable to the European situation.

Separate recent observations by the authors on infections in the lobster Homarus gammarus, however, correspond closely with the American picture. During experiments involving the release of tagged and telson-punched laboratory reared juveniles, a moult of one such lobster was recovered in July 1988 which had been telson-punched in April 1988 - only 3 months previously. The punched right uropod had been almost completely eroded away by a subsequent advancing infection. There were considerable areas of erosion on both the merus and carpus of the left chela, and there were several small punctate lesions $(<1 \mathrm{~mm}$ diameter) on the dorsal mid line of the carapace and on the first segment of the abdomen. The lesions were all characteristically rusty brown, and the endocuticular membrane had been left intact, with small areas of blackening mainly in the central region. The lesions were visible from the inner surface of the exoskeleton, but the wound had not penetrated. This is the classical American picture, and has not been observed to date in the 'wild' lobsters, many of considerable size, which have been handled. It may be significant that this was a hatchery lobster, and had suffered the severe trauma in the laboratory of being tail-punched. Presumably the progressive loss of the uropod necessitated a continual regeneration of the endocuticular membrane in order to conserve body tissues; the same process may serve to isolate lesions elsewhere. There was no sign of any gill damage or infection of the endophragmal skeleton. 


\section{REFERENCES}

Abbott, O. J., 1977. Black necrosis in brown shrimp, Crangon crangon. - In Problems of a small estuary. - Proc. Symposium Burry Inlet (S. Wales), $10 \mathrm{pp}$.

Ayres, P. A. \& E. Edwards, 1982. Notes on the distribution of 'Black Spot' shell disease in crustacean fisheries. - Chemistry in Ecology 1: 125-130.

Bright, B. B., F. E. Durham \& J. W. Knudsen, 1960. King crab investigations of Cook Inlet, Alaska. - Unpublished report cited in Sindermann \& Rosenfield (1967).

Caullery, M., 1952. Parasitism and Symbiosis. - London. 340 pp.

Comely, C. A. \& A. D. Ansell, 1988. Population density and growth of Echinus esculentus L. on the Scottish west coast. - Estuar. coast. Shelf Sci. 27: 311-324.

Cook, D. W. \& S. R. Lofton, 1973. Chitinoclastic bacteria associated with shell disease in Penaeus shrimp and the blue crab (Callinectes sapidus). - J. Wildlife Diseases 9: 154-159.

Crothers, J. H., 1968. The biology of the shore crab Carcinus maenas (L.) 2. The life of the adult crab. - Fld. Stud. 2: 579-614.

Fisher, W. S., 1977. Shell disease of lobsters. - In: C. J. Sindermann (ed.): Disease, Diagnosis and Control in North American Marine Aquaculture. Dev. Aquacult. Fish. Sci. 6: 158-162.

Fisher, W. S., T. R. Rosemark \& E. H. Nilson, 1976. The susceptibility of cultured American lobsters to a chitinolytic bacterium. - Proc. ann. meeting World Maricult. Soc. 7: 511-520.

Fisher, W. S., E. H. Nilson, J. F. Steenbergen \& D. V. Lightner, 1978. Microbial disease of cultured lobsters; a review. - Aquaculture 14: 115-140.

Gopalan, U. K. \& J. S. Young, 1975. Incidence of shell disease in shrimp in the New York Bight. - Mar. Poll. Bull: 6: 149-153.

Hess, E., 1937. A shell disease in lobsters (Homarus americanus) caused by chitinivorous bacteria. J. biol. Bd Can. 3: 358-362.

Lightner, D. V., 1977. Brown spot (Shell) disease of shrimps, pp. 27-30. Black gill disease of shrimps, pp. 61-64. - In C. J. Sindermann (ed.): Disease Diagnosis and Control in American Marine Aquaculture. Dev. in Aquacult. and Fish. Sci. 6.

Mann, H. \& Pieplow, 1938. Die Brandfleckenkrankheit bei Krebsen und ihre Eregger. - Z. Fisch. 36: $225-240$.

McIntosh, N., 1963. A study of black necrosis on the edible crab Cancer pagurus. - Torry Research Station, Aberdeen. Unpubl. Report, 13 pp.

Pearson, J., 1908. Cancer. - Memoirs, Liverpool Marine Biology Committee, 16: 223 pp.

Perkins, E. J., 1967. Some aspects of the biology of Carcinus maenas (L). - Trans. Dumfrieshire and Galloway Natural History and Antiquarian Society, Ser. 3 44: 46-56.

Rinaldo, R. G. \& Yevich, 1974. Black Spot Gill Syndrome of the Northern Shrimp Pandalus borealis. - J. Invert. Path. 24: 224-233.

Roald, O. R., J. Aursja \& T. Hastein, 1981. Occurrence of shell disease in lobsters, Homarus gammarus (L), in the southern part of Oslofjord, Norway. - Fisk. Dir. Skr. ser. Havunders. 17: 153-160.

Rosen, B., 1967. Shell disease of the blue crab, Callinectes sapidus. - J. Invert. Path. 9: 348-353.

Rosen, B., 1970. Shell disease of aquatic crustaceans. - In S. F. Snieszko (ed.): Symposium on Diseases in Fishes and Shellfishes. Special publ. American Fish. Soc. 5: 409-415.

Sawyer, W. H. \& C. C. Taylor, 1949. The effect of shell disease on the gill and chitin of the lobster (Homarus americanus). - Dept. Sea and Shore Fisheries. Augusta, Maine. Res. Bull. 11.

Schlotfeldt, J. J., 1972. Jahreszeitliche Abhängigkeit der "Schwarzfleckenkrankheit" bei der Garnele, Crangon crangon (L). - Ber. dt. wiss. Kommn Meeresforsch. 22: 397-399

Sindermann, C. J., 1977. Shell disease of blue crab. In C. J. Sindermann (ed.): Disease Diagnosis and Control in North American marine aquaculture. Dev. Aquacult. Fish. Sci. 6: 109-112. 
Sindermann, C. J. \& A. Rosenfield, 1967. Principal diseases of commercially important marine bivalve mollusca and crustacea. - U. S. Fish. Bull. 66: 335-385.

Uzmann, J. R. \& E. D. Haynes, 1968. A mycosis of the gills of the Pandalid shrimp Dichelopandalus leptocerus. - J. Invert. Path. 12: 275-277.

Whyman, S., R. Uglow \& P. Macmullen, 1985. A study of mortality rates of the velvet crab during holding and transport. - S. F. I. A. Tech. Rept. 259, Edinburgh, UK.

Young, J. S. \& J. B. Pearce, 1975. Shell disease in crabs and lobsters from New York Bight. - Mar. Poll. Bull. 6: 101-105. 